\title{
IgA-Dominant Postinfectious Glomerulonephritis: A New Twist on an Old Disease
}

\author{
Samih H. Nasra ${ }^{a}$ Vivette D. D'Agati ${ }^{b}$ \\ a Department of Laboratory Medicine and Pathology, Mayo Clinic, Rochester, Minn., and ${ }^{\text {b}}$ Department of \\ Pathology, Columbia University, College of Physicians and Surgeons, New York, N.Y., USA
}

\section{Key Words}

Staphylococcus - Postinfectious glomerulonephritis $\cdot \lg \mathrm{A}$ nephropathy

\begin{abstract}
IgA-dominant acute postinfectious glomerulonephritis (APIGN) is an increasingly recognized morphologic variant of APIGN, particularly in the elderly. In contrast to classic APIGN, in which there is typically glomerular deposition of $\lg G$ and C3 or C3 only, $\lg A$ is the sole or dominant immunoglobulin in IgA-dominant APIGN. Because the vast majority of reported cases occur in association with staphylococcal infections, the alternative designation 'IgA-dominant acute poststaphylococcal glomerulonephritis' has been applied. Diabetes is a major risk factor, likely reflecting the high prevalence of staphylococcal infection in diabetics, particularly involving skin. Patients typically present with severe renal failure, proteinuria and hematuria. Prognosis is guarded with less than a fifth of patients fully recovering renal function. This variant of APIGN must be distinguished from IgA nephropathy. Features that favor IgA-dominant APIGN over IgA nephropathy include initial presentation in older age or in a diabetic patient, acute renal failure, intercurrent culture-documented staphylococcal infection, hypocomplementemia, diffuse glomerular endocapillary hypercellularity with prominent
\end{abstract}

neutrophil infiltration on light microscopy, stronger immunofluorescence staining for $\mathrm{C} 3$ than $\lg \mathrm{A}$, and the presence of subepithelial humps on electron microscopy. The pathogenetic mechanism of selective lgA deposition in patients with poststaphylococcal glomerulonephritis likely involves specific host responses to the inciting pathogen.

Copyright $\odot 2011$ S. Karger AG, Basel

\section{Introduction}

Acute postinfectious glomerulonephritis (APIGN) is an immune-mediated form of glomerulonephritis that most commonly affects children. Classically, APIGN develops following streptococcal upper respiratory tract or skin infections $[1,2]$. More recently, other sites of infection, including skin, lung and heart, and other organisms, particularly Staphylococcus and Gram-negative bacteria, have been linked to APIGN in adults and elderly patients [3-5]. In the developed countries, Staphylococcus has become 3 times more common than Streptococcus as the responsible infectious agent for APIGN in the elderly population [3].

The classic glomerular pattern of injury associated with staphylococcal infection, particularly Staphylococcus aureus, is identical to that seen after streptococcal in-

\section{KARGER}

Fax +4161306 1234

E-Mail karger@karger.ch

www.karger.com
() 2011 S. Karger AG, Basel

1660-2110/11/1191-0018\$38.00/0

Accessible online at:

www.karger.com/nec
Samih H. Nasr, MD

Mayo Clinic

Division of Anatomic Pathology, Hilton 10-20

200 First Street, SW, Rochester MN 55905 (USA)

Tel. +1 507284 1868, E-Mail nasr.samih@ mayo.edu 
fection, including diffuse endocapillary proliferative and exudative glomerulonephritis on light microscopy (LM), glomerular immune deposits that stain for either IgG and $\mathrm{C} 3$ or C3 only on immunofluorescence (IF), and 'humpshaped' subepithelial deposits on electron microscopy (EM) $[1,2]$. A less frequent pattern that resembles membranoproliferative glomerulonephritis type 1 by LM with glomerular deposits of IgM and C3 or IgG and C3 occurs in patients with ventriculovascular shunt infection by Staphylococcus epidermidis $[1,2]$.

In 2003, we described 5 cases of APIGN that showed diffuse endocapillary proliferative glomerulonephritis on $\mathrm{LM}$, intense deposits of IgA as the sole or dominant immunoglobulin on IF, and mesangial and subepithelial deposits on EM [6]. All 5 cases occurred following staphylococcal infection, were associated with hypocomplementemia and were superimposed on diabetic nephropathy. We termed this novel immunopathologic form of APIGN 'IgA-dominant APIGN' [6]. To date, 49 cases of IgA-dominant APIGN have been reported in the English literature, 24 of which were from our group [3, 6-14]. Most of the reports originated from the US, Japan and Taiwan. The vast majority of these cases were in patients with staphylococcal infection and many occurred de novo, without underlying diabetic nephropathy. Here we review the clinical-pathologic features, outcome, and differential diagnosis of this increasingly recognized form of APIGN.

Tables 1 and 2 summarize the compiled data from 49 reported cases of IgA-dominant APIGN. Of note, there have been additional reports of IgA-dominant or codominant glomerulonephritis following staphylococcal infection that lacked any diagnostic features of APIGN, such as endocapillary hypercellularity, subepithelial deposits or hypocomplementemia [11, 15-18], making it impossible to distinguish them from primary IgA nephropathy (see 'Differential Diagnosis of IgA-Dominant APIGN'). Therefore, to avoid potential ambiguity, we have excluded the latter cases from this review.

\section{Clinical Features of IgA-Dominant APIGN}

IgA-dominant APIGN is most frequent in older patients. The average age at diagnosis was 60 years (reported range: $16-85)$ and $61 \%$ of the reported patients were elderly ( $\geq 65$ years of age; table 1 ). In our recent report of 109 elderly patients with APIGN, $17 \%$ had this variant compared to $5 \%$ in the control group of 57 younger adult patients $(p=0.045)$ [3]. There have been no reported cases of IgA-dominant APIGN in children. There is a male predominance of 3.9:1, which is higher than the male-tofemale ratio of 2:1 reported for poststreptococcal glomerulonephritis [19]. Most patients were Caucasian (53\%) and Asian (26\%), although a few African Americans, Hispanics and Native Americans with this disease have also been described [3, 7-14]. Underlying diabetes mellitus was present in 27 patients (55\%). Less frequently reported predisposing conditions to infection include malignancy (6\%), IV drug use (4\%), alcoholism (4\%), HIV infection (2\%) and atopic dermatitis (2\%).

The most common site of infection is skin, reported in $51 \%$ of patients in whom the site of infection was identified (table 1). The types of skin infections have included cellulitis (which was by far the most frequent and primarily involved the lower extremities), surgical wound infections, skin abscesses and IV line infection [3]. A variety of other sites have also been reported, including lung, urinary tract, bone, heart, deep-seated abscesses and upper respiratory tract. The infectious agent was identified in 37 reported patients (76\%) and was Staphylococcus in all but 2 cases, justifying the term 'IgA-dominant poststaphylococcal glomerulonephritis' as an alternative designation for this variant of APIGN. The 2 exceptions were both patients with urinary tract infections, one caused by combined infection with Escherichia coli and Enterococcus and the other by Enterobacter cloacae [3]. Of the 35 reported patients with staphylococcal infection, only 2 had coagulase-negative Staphylococcus (S. epidermidis) [6]. The remaining 33 patients (94\%) had S. aureus, including methicillin-resistant $S$. aureus (MRSA) in 18 patients and methicillin-sensitive S. aureus in 15 patients (table 1). The mean time from clinical onset of infection to renal disease was 4 weeks (reported range: 0-16). In some cases, the diagnosis of infection was made at the time of renal biopsy diagnosis, indicating that infection may go unrecognized for some time [3].

Clinical renal presentations included renal failure (acute or rapidly progressive), hematuria, proteinuria and hypertension. The peak serum creatinine of reported patients ranged from 1.2 to $14.5 \mathrm{mg} / \mathrm{dl}$ (mean: $4.0 \mathrm{mg} / \mathrm{dl}$; table 1$)$. Only 1 patient (2\%) had a peak serum creatinine in the normal range, and $78 \%$ of patients had a peak serum creatinine $>4 \mathrm{mg} / \mathrm{dl}$. Proteinuria is a universal presenting feature (reported range: $0.15-15 \mathrm{~g} /$ day), and was nephrotic range in $51 \%$ of patients. Nephrotic syndrome was present in $40 \%$ of patients with available data. Hematuria is a consistent finding depending on how diligently it is sought, and a quarter of patients developed gross hematuria. Sixty-nine percent of patients had hypocomplementemia. 


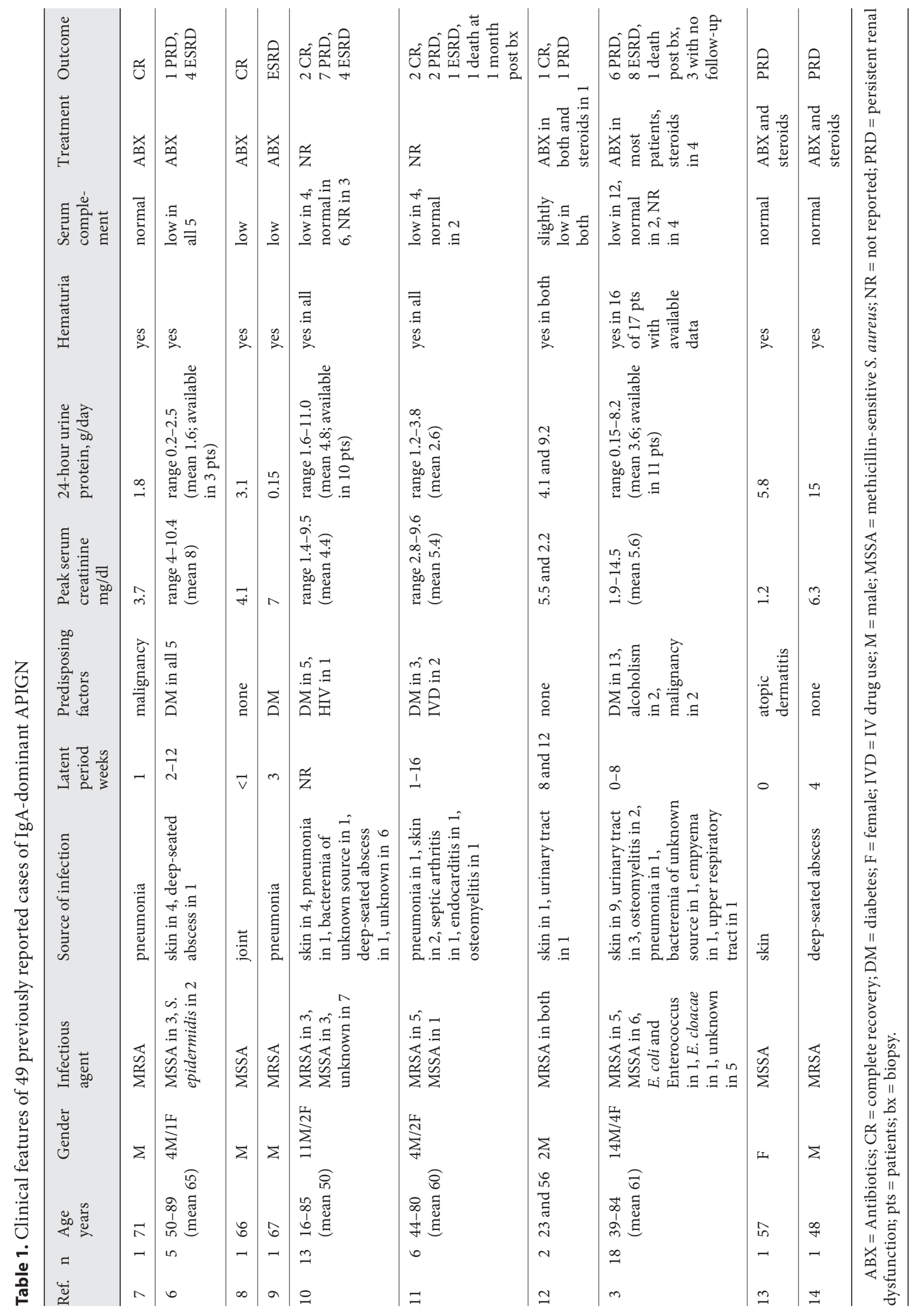


Table 2. Pathological features of 49 previously reported cases of IgA-dominant APIGN

\begin{tabular}{|c|c|c|c|c|c|c|c|}
\hline Ref. & $\mathrm{n}$ & $\begin{array}{l}\text { Glomerular pattern } \\
\text { by LM }\end{array}$ & $\begin{array}{l}\text { IgA staining } \\
\text { relative to other } \\
\text { Ig by IF }\end{array}$ & $\begin{array}{l}\text { C3 staining } \\
\text { intensity compared } \\
\text { to IgA by IF }\end{array}$ & $\begin{array}{l}\text { C1q staining } \\
\text { by IF }\end{array}$ & $\begin{array}{l}\text { Kappa staining } \\
\text { intensity compared } \\
\text { to lambda by IF }\end{array}$ & Location of deposits by EM \\
\hline 7 & 1 & mesangial GN & dominant & not reported & negative & not performed & $\begin{array}{l}\text { subepithelial, subendothelial, } \\
\text { mesangial }\end{array}$ \\
\hline 6 & 5 & endocapillary GN in 5 & $\begin{array}{l}\text { sole in } 3 \text {, dominant } \\
\text { in } 2\end{array}$ & $\begin{array}{l}\text { stronger in } 3 \text {, } \\
\text { equal in } 2\end{array}$ & negative in 5 & $\begin{array}{l}\text { equal in } 3 \text {, weaker } \\
\text { in } 2\end{array}$ & $\begin{array}{l}\text { subepithelial in } 5 \text {, } \\
\text { subendothelial in } 4 \text {, } \\
\text { mesangial in } 5\end{array}$ \\
\hline 8 & 1 & endocapillary GN & codominant & equal & positive & equal & subendothelial, mesangial \\
\hline 9 & 1 & endocapillary GN & dominant & equal & positive & weaker & $\begin{array}{l}\text { subepithelial, subendothelial, } \\
\text { mesangial }\end{array}$ \\
\hline 10 & 13 & $\begin{array}{l}\text { endocapillary GN in } 6 \text {, } \\
\text { mesangial GN in } 7\end{array}$ & sole or dominant & $\begin{array}{l}\text { mean intensity } \\
\text { stronger }\end{array}$ & $\begin{array}{l}\text { positive in } 2 \text {, } \\
\text { negative in } 11\end{array}$ & $\begin{array}{l}\text { equal in } 12 \text {, } \\
\text { stronger in } 1\end{array}$ & $\begin{array}{l}\text { subepithelial and mesangial } \\
\text { in } 13 \text {, subendothelial in } 6\end{array}$ \\
\hline 11 & 6 & mesangial GN in 6 & $\begin{array}{l}\text { sole in } 1 \text {, dominant } \\
\text { in } 4 \text {, codominant } \\
\text { in } 1\end{array}$ & $\begin{array}{l}\text { equal in } 5 \text {, } \\
\text { weaker in } 1\end{array}$ & $\begin{array}{l}\text { positive in } 2, \\
\text { negative in } 4\end{array}$ & not performed & $\begin{array}{l}\text { mesangial in } 6 \text {, subepithelial } \\
\text { in } 3\end{array}$ \\
\hline 12 & 2 & $\begin{array}{l}\text { mesangial GN in } 1 \text {, } \\
\text { crescentic GN in } 1\end{array}$ & sole in both & not indicated & negative in 2 & not performed & $\begin{array}{l}\text { subepithelial in } 1 \text {, mesangial } \\
\text { in } 2 \text {, subendothelial in } 1\end{array}$ \\
\hline 3 & 18 & $\begin{array}{l}\text { endocapillary GN in } 16 \text {, } \\
\text { mesangial GN in } 1 \text {, } \\
\text { crescentic GN in } 1\end{array}$ & $\begin{array}{l}\text { sole in } 12 \text {, dominant } \\
\text { in } 6\end{array}$ & $\begin{array}{l}\text { stronger in } 15 \text {, } \\
\text { equal in } 3\end{array}$ & $\begin{array}{l}\text { positive in } 2, \\
\text { negative in } 16\end{array}$ & $\begin{array}{l}\text { equal in } 8 \text {, weaker } \\
\text { in } 6 \text {, stronger in } 1\end{array}$ & $\begin{array}{l}\text { subepithelial in } 16 \text {, mesangial } \\
\text { in } 16 \text {, subendothelial in } 13\end{array}$ \\
\hline 13 & 1 & endocapillary GN & dominant & not indicated & negative & not performed & not performed \\
\hline 14 & 1 & endocapillary GN & dominant & weaker & negative & equal & subendothelial, mesangial \\
\hline
\end{tabular}

Most reported patients with IgA-dominant APIGN were treated appropriately with antibiotics, and 7 also received steroids. Despite therapy directed to the infection, prognosis was guarded: $16 \%$ of reported patients had full recovery (normalization of serum creatinine to baseline levels or to a creatinine $\leq 1.2 \mathrm{mg} / \mathrm{dl}$ ), $43 \%$ had persistent renal dysfunction and $41 \%$ progressed to ESRD (table 1). Two thirds of patients who progressed to ESRD had underlying diabetic glomerulosclerosis, which likely contributed to the poor outcomes. Although there has been no systematic evaluation of treatment options, the limited available evidence does not provide any support for the use of corticosteroids in addition to antistaphylococcal therapy.

\section{Pathology of IgA-Dominant APIGN}

The most frequent histologic pattern of glomerular injury on LM in IgA-dominant APIGN is endocapillary proliferative and exudative glomerulonephritis, identi- cal to that seen in poststreptococcal glomerulonephritis (fig. 1). This pattern was present in $63 \%$ of reported cases (table 2). In some cases the glomerulonephritis occurs superimposed on diabetic nephropathy, whereas many others have presented as an isolated de novo glomerular disease. Pure mesangial proliferative glomerulonephritis was described in $33 \%$ of reported patients, while crescentic glomerulonephritis was described in only $4 \%$ of cases.

On IF, IgA staining was the sole or dominant immunoglobulin deposited in glomeruli in all but 2 reported cases, with or without weaker staining for IgG and/or IgM. The 2 exceptions displayed equally intense (codominant) glomerular staining for IgA and IgG. There is typically high-intensity staining for $\mathrm{C} 3$, which is stronger than IgA in the majority of cases (table 2). This immunopathologic feature aids in the distinction of IgA-dominant APIGN from IgA nephropathy, in which C3 staining is typically weaker than IgA staining [1]. Positive staining for C1q is uncommon, reported in only $16 \%$ of cases, and is usually of weak intensity. In IgA nephropathy, there is usually greater mesangial staining for lambda than kap- 


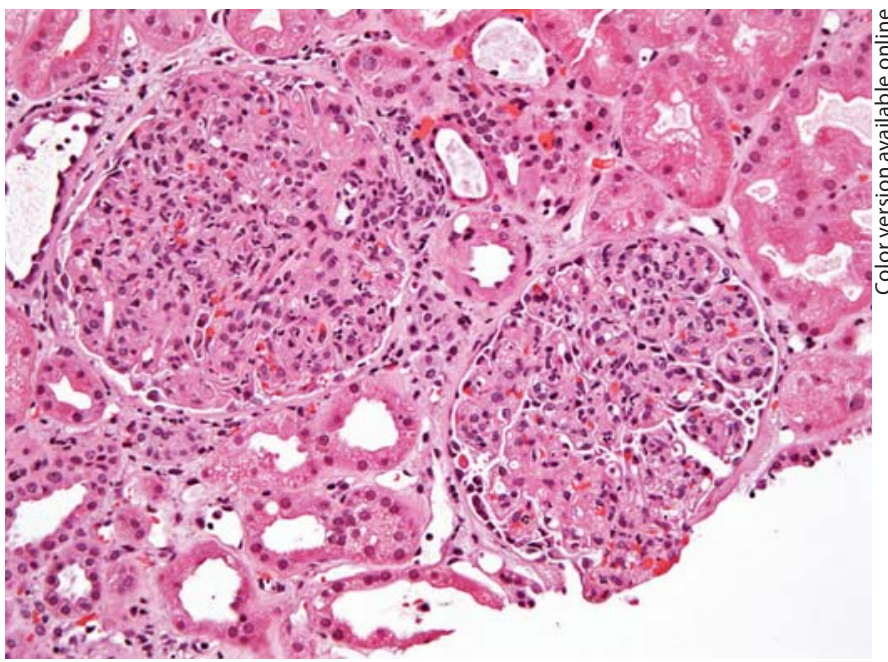

Fig. 1. The two glomeruli depicted are from a diabetic patient with acute renal failure following staphylococcal pneumonia. There is marked global endocapillary hypercellularity with numerous infiltrating neutrophils causing obliteration of the capillary lumina (hematoxylin and eosin: $\times 200$ ).

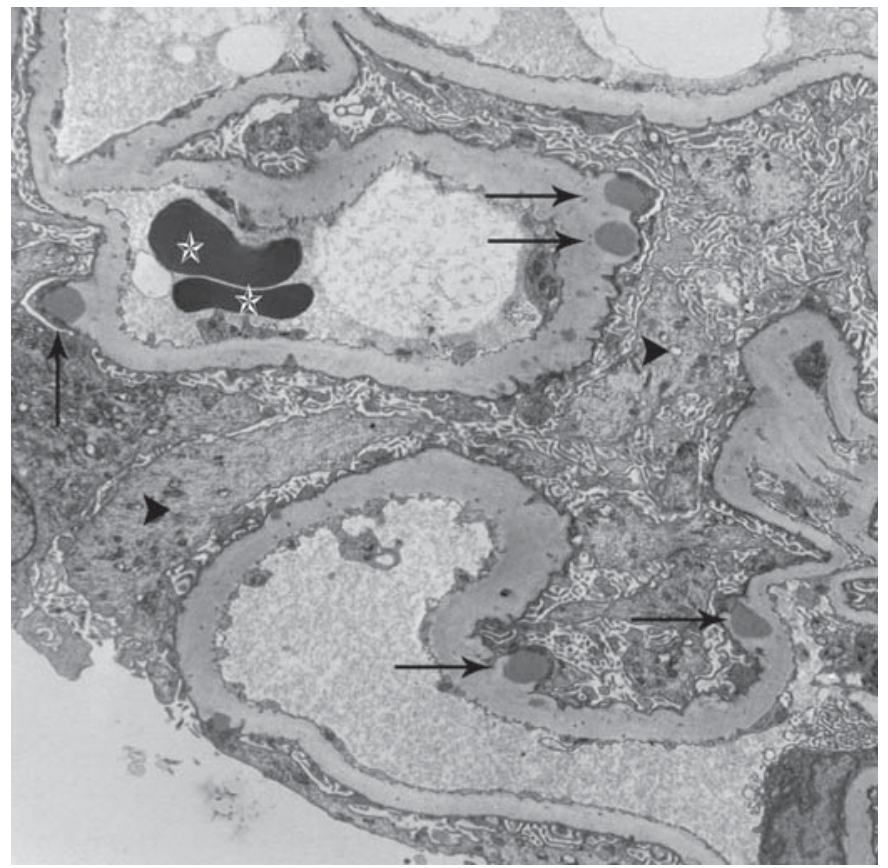

Fig. 3. This electron micrograph from a diabetic patient with IgAdominant APIGN demonstrates several hump-shaped subepithelial electron-dense deposits (arrows). The glomerular basement membrane is thickened, consistent with underling diabetic glomerulosclerosis. Podocytes (arrowheads) exhibit moderate foot process effacement. The stars indicate intracapillary erythrocytes $(\times 3,400)$.

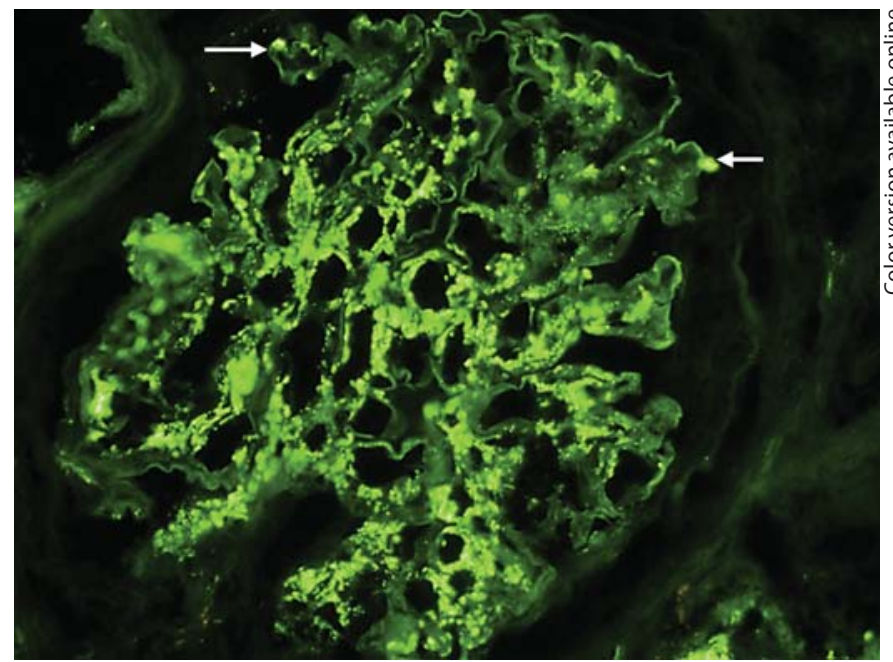

Fig. 2. IgA immunostaining in IgA-dominant APIGN. There is bright, coarsely granular glomerular staining: globally in the mesangium and segmentally in the glomerular capillary walls in the distribution of subepithelial humps (arrows; IF: $\times 400$ ).

pa, which reflects the lower than normal serum IgA1 kappa:lambda ratio [20]. In contrast, staining for kappa was equal or stronger compared to lambda in $69 \%$ of reported cases of IgA-dominant APIGN, which is another useful immunopathologic feature in the distinction from IgA nephropathy $[3,10]$. The quality and texture of the IF staining are also helpful, with many cases exhibiting punctate deposits corresponding to the presence of peripheral capillary wall humps and mesangial deposits (often referred to as 'starry sky' pattern) $[3,21]$ (table 2; fig. 2).

Ultrastructurally, mesangial electron-dense deposits were present in $96 \%$ of reported cases. Importantly, subepithelial deposits, frequently exhibiting a 'hump-shaped' appearance, were also common, having been identified in $83 \%$ of the reported cases (fig. 3). Subendothelial deposits are less frequent, reported in just over half of patients, and are typically small and rare.

\section{Pathogenesis of IgA-Dominant APIGN}

The pathogenetic mechanism of the selective IgA deposition in patients with poststaphylococcal glomerulonephritis is not understood, but is likely to involve specific host-pathogen interactions. Some of the reported cases had increased serum IgA levels, suggesting activa- 
tion of selective IgA immune responses [6, 12]. Koyama et al. [17] found that patients with MRSA-associated glomerulonephritis had polyclonal increases of serum IgA and IgG, high levels of circulating Ig A-IgG immune complexes, and massive $\mathrm{T}$ cell activation. They speculated that post-MRSA glomerulonephritis may be induced by staphylococcal enterotoxin, which acts as a superantigen. Superantigens bypass normal antigen presentation by binding directly to the major histocompatibility class II molecules on antigen-presenting cells and to the variable portion of the beta chain of T cells. This leads to massive $\mathrm{T}$ cell activation and production of high amounts of proinflammatory cytokines, including those with class-switching functions $[7,17,18,22]$. Of interest, IgAdominant APIGN also may develop following coagulasenegative Staphylococcus, which does not produce enterotoxin, suggesting a potential pathogenetic role for particular staphylococcal cell surface antigen(s).

Recently, the same Japanese group detected S. aureus envelope antigen designated 'probable adhesin' in the glomeruli of $70 \%$ of patients with IgA nephropathy, Henoch-Schönlein purpura (HSP) and post-MRSA glomerulonephritis colocalizing with the IgA deposits [23]. They proposed 'probable adhesin' as a new candidate antigen for the induction of IgA immune responses in IgA nephropathy. They subsequently induced IgA-like glomerulonephritis in Balb/c mice by immunization with antigens derived from $S$. aureus mixed with Freund's incomplete adjuvant [24]. Of note, glomerular IgA and C3 deposition can also be induced in mice by administration of several strains of Gram-negative bacteria cell wall components, including Pseudomonas aeruginosa, E. coli, Haemophilus influenzae and Klebsiella pneumoniae [25]. Because mice have significant differences in IgA structure, synthesis and clearance compared to humans, caution should be used when extrapolating from the results of these murine studies.

Interestingly, the outer membrane of $H$. parainfluen$z a e$ has been detected in the glomeruli of patients with IgA nephropathy [26]. These findings are consistent with the rare occurrence of IgA-dominant APIGN in association with certain Gram-negative bacteria [3]. It is unknown if the IgA deposited in glomeruli of patients with IgA-dominant APIGN is predominantly of the IgA1 subclass, as occurs in patients with primary IgA nephropathy. Likewise, it remains to be determined whether these patients have aberrant IgA molecule glycosylation of the type described in patients with IgA nephropathy.

Over half of patients with IgA-dominant APIGN are diabetics. It is possible that the diabetic milieu plays a role
Table 3. Features favoring IgA-dominant APIGN over IgA nephropathy

Clinical features

Intercurrent culture-documented staphylococcal infection

Hypocomplementemia

Presentation in older age

History of diabetes mellitus

Acute renal failure at presentation

Pathologic features

Endocapillary proliferation with neutrophil infiltration on LM

Stronger staining for C3 than IgA on IF

'Starry sky' pattern on IF

Subepithelial 'humps' on EM

in the mounting of an IgA-dominant immune response. Multiple studies have shown that diabetics have increased serum IgA and IgA-containing circulating immune complexes compared with nondiabetics [27-31]. RodriguezSegade et al. [28] found high serum concentrations of IgA in $23.1 \%$ of diabetics, which were significantly greater in those with end-organ complications of retinopathy, nephropathy and neuropathy than in those without these complications. Similarly, Ohmuro et al. [31] found that the serum levels of IgA in patients with type 2 diabetes were elevated compared with those in healthy adults, and were significantly higher in diabetics with nephropathy than in those without nephropathy. Proposed (but unproven) explanations for the high serum IgA levels in diabetics include decreased IgA hepatic clearance caused by serum IgA1 hypersialylation and increased synthesis of IgA in association with subclinical mucosal infection or as a potential immune response to advanced glycation endproducts $[27,32]$.

\section{Differential Diagnosis of IgA-Dominant APIGN}

IgA-dominant APIGN should be distinguished from IgA nephropathy and HSP nephritis. Clinical and histologic features that favor APIGN over IgA nephropathy include initial presentation in older age, acute renal failure at presentation, intercurrent culture-documented staphylococcal infection, depressed serum complement, diffuse endocapillary hypercellularity with prominent neutrophil infiltration on LM, stronger staining for C3 than IgA and lack of lambda predominance on IF, and the presence of subepithelial humps on EM $[6,9,10,33]$ (table 3). When several of the above features, particularly 
hypocomplementemia, diffuse intracapillary neutrophil infiltration and abundant subepithelial humps, are present, IgA-dominant APIGN can be diagnosed with a high degree of certainty. It is extremely unlikely that IgAdominant poststaphylococcal glomerulonephritis represents an exacerbation of pre-existing primary IgA nephropathy, as most of the reported patients were elderly and lacked any prior history of glomerulonephritis [3].

Endocapillary hypercellularity and subepithelial deposits are not uncommon in HSP, which may be difficult to distinguish from APIGN on morphologic grounds. The presence of extrarenal manifestations, including purpura, arthritis, abdominal pain and GI bleeding, and the presence of normal serum complement would support a diagnosis of HSP. Of note, there have been a few reported cases of HSP nephritis following staphylococcal infection $[34,35]$.

It is known that the initial onset of IgA nephropathy or flares of an existing IgA nephropathy may coincide with infections, particularly in the upper respiratory tract. Such cases have been termed 'synpharyngitic glomerulonephritis' based on the absence of a latent period between infection and the development of clinical signs and symptoms of nephritis. In addition, IgA nephropathy can be promoted by IgA overproduction associated with mucosal infections of the bronchial or gastrointestinal tract. Cases of IgA nephropathy have also been reported in patients with underlying HIV infection, in whom IgA immune responses are often activated. Some of the reported patients of poststaphylococcal glomerulonephritis with IgA-dominant or codominant deposits had normal serum complement and showed only mesangial hypercellularity on LM with no subepithelial deposits on
EM $[11,15-18,36]$. We and others favor that these cases likely represent examples of primary IgA nephropathy (in which an intercurrent infection has caused exacerbation or recrudescence of existing nephritis) rather than true APIGN $[9,10,36]$.

\section{Conclusions}

IgA-dominant APIGN is an increasingly recognized morphologic variant of APIGN that typically occurs in association with staphylococcal infection. It is most common in the elderly and in diabetics. Patients typically present with severe renal failure, proteinuria and hematuria. Hypocomplementemia is present in the majority of patients. Histologically, most cases exhibit endocapillary hypercellularity and neutrophil infiltration, although some have only mesangial proliferation. By definition, $\operatorname{Ig} \mathrm{A}$ is the sole or dominant immunoglobulin deposited in the glomeruli. Although IgA-dominant APIGN appears to be a one-shot disease (without the recurrences and exacerbations that characterize primary IgA nephropathy), prognosis is guarded with less than a fifth of patients fully recovering renal function. This poor prognosis is likely due to older age and comorbidities such as diabetes in the population at risk. Greater awareness of this entity among renal pathologists and nephrologists is needed to distinguish this condition from the more common entity of IgA nephropathy. Future studies directed to pathogenesis may help to identify the nephritogenic staphylococcal antigen(s) and the immunologic basis for the dominant IgA host response.

\section{References}

1 D’Agati VD, Jennette JC, Silva FG: Atlas of Nontumor Pathology: Non-Neoplastic Kidney Diseases. Washington, American Registry of Pathology-Armed Forces Institute of Pathology, 2005, pp 269-321.

2 Nadasdy T, Silva FG: Acute postinfectious glomerulonephritis and glomerulonephritis caused by persistent bacterial infection; in: Jennette JC, Olson JL, Schwartz MM, Silva FG (eds): Heptinstall's Pathology of the Kidney, ed 6. Philadelphia, Lippincott Williams \& Wilkins, 2007, pp 321-396.

-3 Nasr SH, Fidler ME, Valeri AM, Cornell LD, Sethi S, Zoller A, Stokes MB, Markowitz GS, D'Agati VD: Postinfectious glomerulonephritis in the elderly. J Am Soc Nephrol 2011;22:187-195.
Nasr SH, Markowitz GS, Stokes MB, Said SM, Valeri AM, D’Agati VD: Acute postinfectious glomerulonephritis in the modern era: experience with 86 adults and review of the literature. Medicine (Baltimore) 2008; 87:21-32.

5 Montseny JJ, Meyrier A, Kleinknecht D, Callard P: The current spectrum of infectious glomerulonephritis. Experience with 76 patients and review of the literature. Medicine (Baltimore) 1995;74:63-73.

-6 Nasr SH, Markowitz GS, Whelan JD, Albanese JJ, Rosen RM, Fein DA, Kim SS, D’Agati VD: IgA-dominant acute poststaphylococcal glomerulonephritis complicating diabetic nephropathy. Hum Pathol 2003;34:12351241.
Yoh K, Kobayashi M, Hirayama A, Hirayama K, Yamaguchi N, Nagase S, Koyama A: A case of superantigen-related glomerulonephritis after methicillin-resistant Staphylococcus aureus (MRSA) infection. Clin Nephrol 1997;48:311-316.

Long JA, Cook WJ: IgA deposits and acute glomerulonephritis in a patient with staphylococcal infection. Am J Kidney Dis 2006; 48:851-855.

-9 Nasr SH, Share DS, Vargas MT, D’Agati VD, Markowitz GS: Acute poststaphylococcal glomerulonephritis superimposed on diabetic glomerulosclerosis. Kidney Int 2007; 71:1317-1321. 
-10 Haas M, Racusen LC, Bagnasco SM: IgAdominant postinfectious glomerulonephritis: a report of 13 cases with common ultrastructural features. Hum Pathol 2008; 39:1309-1316.

$\checkmark 11$ Wen YK, Chen ML: The significance of atypical morphology in the changes of spectrum of postinfectious glomerulonephritis. Clin Nephrol 2010;73:173-179.

-12 Nagaba Y, Hiki Y, Aoyama T, Sano T, Matsuo T, Shimizu T, Tateno S, Sakamoto H, Kamata K, Shigematsu H, Higashihara M, Kobayashi Y: Effective antibiotic treatment of methicillin-resistant Staphylococcus aureus-associated glomerulonephritis. Nephron 2002;92:297-303.

$\checkmark 13$ Handa T, Ono T, Watanabe H, Takeda T, Muso E, Kita T: Glomerulonephritis induced by methicillin-sensitive Staphylococcus aureus infection. Clin Exp Nephrol 2003;7:247249.

-14 Okuyama S, Wakui H, Maki N, Kuroki J, Nishinari T, Asakura K, Komatsuda A, Sawada K: Successful treatment of postMRSA infection glomerulonephritis with steroid therapy. Clin Nephrol 2008;70:344347.

-15 Kai H, Shimizu Y, Hagiwara M, Yoh K, Hirayama K, Yamagata K, Ohba S, Nagata M, Koyama A: Post-MRSA infection glomerulonephritis with marked Staphylococcus aureus cell envelope antigen deposition in glomeruli. J Nephrol 2006;19:215-219.

-16 Spector DA, Millan J, Zauber N, Burton J: Glomerulonephritis and Staphylococcal aureus infections. Clin Nephrol 1980;14:256261.

- 17 Koyama A, Kobayashi M, Yamaguchi N, Yamagata K, Takano K, Nakajima M, Irie F, Goto M, Igarashi M, Iitsuka T, Aoki Y, Sakurai H, Sakurayama N, Fukao K: Glomerulonephritis associated with MRSA infection: a possible role of bacterial superantigen. Kidney Int 1995;47:207-216.
18 Satoskar AA, Nadasdy G, Plaza JA, Sedmak D, Shidham G, Hebert L, Nadasdy T: Staphylococcus infection-associated glomerulonephritis mimicking IgA nephropathy. Clin. J Am Soc Nephrol 2006;1:1179-1186.

19 Baldwin DS, Gluck MC, Schacht RG, Gallo G: The long-term course of poststreptococcal glomerulonephritis. Ann Int Med 1974;80:342-358.

20 Chui SH, Lam CW, Lewis WH, Lai KN Light-chain ratio of serum IgA1 in IgA nephropathy. J Clin Immunol 1991;11:219-223.

21 Sorger K, Gessler U, Hübner FK, Köhler H, Schulz W, Stühlinger W, Thoenes GH, Thoenes W: Subtypes of acute postinfectious glomerulonephritis. Synopsis of clinical and pathological features. Clin Nephrol 1982; 17:114-128.

22 Yoh K, Kobayashi M, Yamaguchi N, Hirayama K, Ishizu T, Kikuchi S, Iwabuchi S, Muro K, Nagase S, Aoyagi K, Kondoh M, Takemura K, Yamagata K, Koyama A: Cytokines and $\mathrm{T}$-cell responses in superantigen-related glomerulonephritis following methicillin-resistant Staphylococcus aureus infection. Nephrol Dial Transplant 2000;15:1170-1174

-23 Koyama A, Sharmin S, Sakurai H, Shimizu Y, Hirayama K, Usui J, Nagata M, Yoh K, Yamagata K, Muro K, Kobayashi M, Ohtani K, Shimizu T, Shimizu T: Staphylococcus aureus cell envelope antigen is a new candidate for the induction of IgA nephropathy. Kidney Int 2004;66:121-132.

-24 Sharmin S, Shimizu Y, Hagiwara M, Hirayama K, Koyama A: Staphylococcus aureus antigens induce IgA-type glomerulonephritis in Balb/c mice. J Nephrol 2004;17:504-511.

25 Endo Y, Kanbayashi H, Hara M: Experimental immunoglobulin A nephropathy induced by Gram-negative bacteria. Nephron 1993; 65:196-205

26 Suzuki S, Nakatomi Y, Sato H, Tsukada H, Arakawa M: Haemophilus parainfluenzae antigen and antibody in renal biopsy samples and serum of patients with IgA nephropathy. Lancet 1994;343:12-16.

-27 Kanauchi M, Kawano T, Dohi K: Serum IgA levels in patients with diabetic nephropathy and IgA nephropathy superimposed on diabetes mellitus. Diabetes Res Clin Pract 2000;48:113-118.
28 Rodriguez-Segade S, Camiña MF, Carnero A, Lorenzo MJ, Alban A, Quinteiro C, Lojo S: High serum IgA concentrations in patients with diabetes mellitus: agewise distribution and relation to chronic complications. Clin Chem 1996;42:1064-1067.

29 Ardawi MS, Nasrat HA, Bahnassy AA: Serum immunoglobulin concentrations in diabetic patients. Diabet Med 1994;11:384-387.

30 Casiglia D, Giardina E, Scarantino G, Triolo G: Increased plasma levels of IgA-IgG immune complexes and anti-F(ab')2 antibodies in patients with type 2 (non insulin-dependent) diabetes mellitus and microangiopathy. Diabetes Res 1990;15:195-200.

-31 Ohmuro H, Tomino Y, Tsushima Y, Shimizu M, Kuramoto T, Koide H: Elevation of serum IgA1 levels in patients with diabetic nephropathy. Nephron 1993;63:355.

32 Vazquez-Moreno L, Candia-Plata MC, Robles-Burgueno MR: Hypersialylated macromolecular serum immunoglobulin A1 in type 2 diabetes mellitus. Clin Biochem 2001;34:35-41.

33 Wen YK, Chen ML: Discrimination between postinfectious IgA-dominant glomerulonephritis and idiopathic IgA nephropathy. Ren Fail 2010;32:572-577.

34 Hirayama K, Kobayashi M, Kondoh M, Muro K, Iwabuchi S, Yoh K, Ishizu T, Kikuchi S, Yamaguchi N, Nagase S, Koyama A: Henoch-Schönlein purpura nephritis associated with methicillin-resistant Staphylococcus aureus infection. Nephrol Dial Transplant 1998;3:2703-2704.

35 Hashimoto M, Nogaki F, Oida E, Tanaka M, Ito-Ihara T, Nomura K, Liu N, Muso E, Fukatsu A, Kita T, Ono T: Glomerulonephritis induced by methicillin-resistant Staphylococcus aureus infection that progressed during puerperal period. Clin Exp Nephrol 2007;11:92-96.

36 Riley AM, Wall BM, Cooke CR: Favorable outcome after aggressive treatment of infection in a diabetic patient with MRSA-related IgAnephropathy.AmJMedSci2009;337:221223. 


\section{Editorial Comment}

Meguid El Nahas, Sheffield

The review by Nasr and D'Agati draws the reader's attention to the changing nature of postinfectious glomerulonephritis. IgA-dominant postinfectious glomerulonephritis is increasingly being recognized. The review highlights the fact that this form of acute glomerulonephritis is more likely to occur in the elderly, the immunocompromised and those with diabetes. It also stresses the association with staphylococcal infections and the range of histological changes including the mesangioproliferative form associated with IgA deposits. A recent review by the same group is also highly recommended [1]. In developing countries, including the Far East, where IgA nephropathy is quite common, it is important to distinguish between postinfectious IgA nephropathy and an acceleration of idiopathic IgA nephropathy or a superimposed infection. In addition to hypocomplementemia and sub- epithelial immune deposits characteristic of postinfectious glomerulonephritis, patients with postinfectious IgA-dominant glomerulonephritis tend to present frequently with acute renal failure when compared to those with idiopathic IgA nephropathy. The poor prognosis and lower recovery rate associated with IgA-dominant postinfectious glomerulonephritis is attributed to the associated comorbidities. Nephrologists should be aware of this entity and include it in the differential diagnosis of elderly patients presenting with acute kidney injury.

Reference 